\title{
Comparison of Transosseous Wiring and Miniplates in Management of Mandibular Parasymphyseal Fractures
}

\author{
Mehreen Razziq ${ }^{1}$, Muhammad Jamal ${ }^{2}$, Irum Mushtaq ${ }^{3}$, Nadia ${ }^{4}$, Laiba Saher ${ }^{5}$ \\ ${ }^{1}$ Dental Surgeon, Qazi Hussain Ahmad Medical Complex, Nowshera, Pakistan \\ ${ }^{2}$ Assistant Professor, Oral and Maxillofacial Surgery, Islamabad Medical and Dental College Islamabad, Pakistan \\ ${ }^{3}$ Head, Department of OMFS, Ayub Medical College/Ayub Teaching Hospital, Abbotabad, Pakistan \\ ${ }^{4}$ Postgraduate Resident, Department of OMFS, Ayub Medical College/Ayub Teaching Hospital, Abbotabad, Pakistan \\ ${ }^{5}$ Postgraduate Resident, Department of OMFS, Islamabad Medical and Dental College, Pakistan
}

\begin{abstract}
A BSTRACT
Background: Mandibular fractures are the most common type of facial fractures in the adult population, accounting for $36 \%-59 \%$ of all maxillofacial injuries and their treatment is one of the most frequent forms of therapy provided by maxillofacial surgeons. The objective of the study was to compare the outcome of transosseous wiring and miniplates in the management of mandibular parasymphyseal fractures in terms of infection and malocclusion.

Material and Methods: This randomized control trial was carried out at Oral and Maxillofacial Department, Ayub Medical College/ Ayub Teaching Hospital Abbottabad. A total of 124 patients were randomly allocated into two groups by lottery method. Patients in group A were subjected to transosseous wiring with maxilla-mandibular fixation. Patients in group B underwent miniplate fixation method. Post-operative wound infection and malocclusion findings at 6 weeks were recorded.

Results: Frequency of post-operative infection and malocclusion at 6 weeks of surgery was slightly more but statistically non-significant in patients of group A undergoing Transosseous wiring method as compared to group B patients experiencing Miniplate technique.

Conclusions: Miniplate osteosynthesis causes slightly less post-operative morbidity in terms of infection and malocclusion as compared to transosseous wiring for the management of mandibular parasymphyseal fractures.

Key words: Infection, Malocclusion, Mandibular parasymphyseal fractures, Miniplates, Transosseous wiring

Authors' Contribution:

${ }^{1-3}$ Conception; Literature research; Mehreen Razziq

manuscript design and drafting; ${ }^{4,5}$ Critical

analysis and manuscript review; Data

analysis; Manuscript Editing.

Cite this article. Razziq M, Jamal M, Mushtaq I, Nadia, Saher L. Comparison of Transosseous Wiring and Miniplates in Management of Mandibular Parasymphyseal Fractures. J

Article info:

Received: November 18, 2019

Accepted: June 3, 2020

Email: Mehreenkamran@gmail.com

Funding Source: Nil Conflict of Interest: Nil
\end{abstract} Islamabad Med Dental Coll.2020; 9(2): 134-139. Doi: 10.35787/jimdc.v9i2.393

\section{Introduction}

Mandibular fractures are the most common type of facial fractures in the adult population, ${ }^{1}$ accounting for $36 \%-59 \%$ of all maxillofacial injuries and their treatment is one of the most frequent forms of therapy provided by maxillofacial surgeons. ${ }^{2}$ The major causes of mandibular fractures include motor vehicle accidents, altercations and falls. These fractures are designated as occurring in the condylar, ramus, angle, body, symphyseal, alveolar, and rarely coronoid process areas. ${ }^{3}$

Fractures at the level of the symphysis and/or parasymphysis are relatively common and account for approximately $20 \%$ of mandibular fractures. 
These fractures are often associated with a second fracture of the mandible, especially in the subcondylar region. ${ }^{4}$ The goals of mandibular fracture management include the restoration of the pre-existing anatomical form, functional occlusion and masticatory function with minimal disability and complications. ${ }^{5}$

The management of mandibular fractures has evolved from a closed approach to a more direct, open approach with experience from orthopedic surgery, relying on direct, anatomical reduction and fixation of these fractures. ${ }^{6}$ Many clinicians advocate the use of maxillomandibular fixation (MMF) technique for the treatment of mandibular fractures due to their non-invasive nature, low financial burden on the patient, ease of availability of material required and ease of instrumentation. ${ }^{7-9}$ Others advocate the use of open reduction techniques using compression plates, transosseous wiring, lagscrews and miniplates. ${ }^{10-12}$ Currently rigid fixation with one or two miniplates has become a widely acceptable method of providing internal fixation and eliminating the need for post-operative maxillomandibular fixation. ${ }^{12,13}$ The advantage of open reduction and internal fixation include early restoration of occlusal function and proper repositioning of fracture with more stable and predictable results. ${ }^{14}$ Complications associated with miniplates and transosseous wiring includes infection, malocclusion, mal-union, non-union, nerve damage and TMJ-dysfunction. ${ }^{15}$ Of these complications, postoperative infection and malocclusion was $15 \%$ and $10 \%$ after transosseous wiring $^{13}$ and $1.5 \%$ and $0.2 \%$ after miniplate osteosynthesis, ${ }^{16}$ respectively.

The indications for the various types of rigid internal fixations have evolved over the years with newest technique offering more advantages than the older surgical methods, without major additional disadvantages. However, due to unavailability and unaffordability of hardware osteosynthesis by some patients, it is not used in some oro-facial injury treatment centers in the third world countries. This has compelled surgeons' practicing in these parts of the world to use the older surgical treatment methods such as transosseous wire osteosynthesis with inter-maxillary fixation for the treatment of these fractures. ${ }^{10}$ The objective of this study was to compare the outcome of transosseous wiring and miniplates in the management of mandibular parasymphyseal fractures in terms of infection and malocclusion.

\section{Material and Methods}

This randomized control trial was carried out at Oral and Maxillofacial Department, Ayub Medical College / Ayub Teaching Hospital Abbottabad from 2nd January, 2015 to 12th June, 2015. Study was conducted after approval of ethical committee of Ayub teaching Hospital Abbottabad. Sample size of 124 cases was calculated (62 in each group) using WHO Calculator with $80 \%$ power of test, $5 \%$ level of significance and $10 \%$ expected percentage of malocclusion in transosseous wiring group ${ }^{13}$ and $0.2 \%$ in miniplate group ${ }^{16}$ for the management of mandibular parasymphyseal fractures. Nonprobability purposive sampling was carried out to induct the patients.

Both male and female patients between 18-50 years of age, presenting within seven days of trauma were included in the study through outdoor and emergency department. They were diagnosed with isolated parasymphyseal fractures on the basis of clinical examination and radiographs (Orthopantomogram). Comminuted mandibular parasymphysis fractures, panfacial trauma, pathological fractures (tumor, cyst) and immunocompromised patients were excluded from the study because these conditions can introduce bias in the study results. The purpose and benefit of the study was explained to the patient and informed written consent was obtained. Detailed 
history, clinical examination and routine preoperative investigations (OPG and PA mandible) of patients were recorded. Preoperative extra-oral and intra-oral pictures were taken with photographic recording of occlusion. The surgical procedure was carried out aseptically under general endotracheal anesthesia (GETA) using nasotracheal intubation. Prophylactic antibiotics and Dexamathasone were given. After infiltration with 2\% lignocaine (containing 1:100,000 epinephrine) and a waiting period of ten minutes, fracture segments were exposed, reduced and fixed through intraoral buccal vestibular incision, except those with pre-existing skin laceration.

All patients were randomly allocated into two groups by lottery method. Patients in group A were subjected to transosseous wiring with maxillamandibular fixation. Patients in group $B$ were underwent miniplate fixation method. Miniplate of five-hole was adapted at the lower border, while four-hole miniplate was adapted at the upper border. Screws of $2 \mathrm{~mm}$ diameter with $7 \mathrm{~mm}$ length were used. All the surgical procedures were performed by the principal investigator.

Postoperative radiographs were obtained before discharge. All the patients were discharged within 8-12 hours of the procedure, with antibiotics, analgesics and strict instructions regarding fluid diet and maintaining oral hygiene till notified further. Patients were called for follow-up on the second, fourth and sixth week by the principal investigator. The outcome variables were malocclusion and infection. The successful outcome measures were described as successful bone healing and acceptable occlusion. Post-operative wound infection and malocclusion findings at 6 weeks were recorded on a proforma based on combined clinical and radiographic analysis.

The collected data was entered and analyzed through Statistical Package for Social Sciences
(SPSS), version 10.0 (SPSS Inc., Chicago, IL, USA). The qualitative variables including gender and postoperative complications i.e. infection and malocclusion were calculated as frequency and percentages. The quantitative data like age was computed as means and standard deviation. Infection and malocclusion were stratified among age and sex to see the effect modification. The variables were compared through chi square test/fisher's exact test. A $P$-value of $\leq 0.05$ was considered statistically significant.

\section{Results}

Out of total 124 patients, ratio of male to female was 1.6:1 in group $A$ and 1.5:1 in group B. Mean age of patients in group $A$ and $B$ was $32 \pm 1.62$ and $33 \pm 2.53$ years respectively. Maximum number of patients were from 21-40 years of age in both groups (Table I).

\begin{tabular}{|c|c|c|}
\hline Variables & $\begin{array}{c}\text { Group A (n=62) } \\
n(\%)\end{array}$ & $\begin{array}{c}\text { Group B (n=62) } \\
n(\%)\end{array}$ \\
\hline \multicolumn{3}{|l|}{ Gender } \\
\hline Male & $38(62)$ & $37(60)$ \\
\hline Female & $24(38)$ & $25(40)$ \\
\hline \multicolumn{3}{|c|}{ Age (Years) } \\
\hline$\leq 20$ & $11(18)$ & $10(16)$ \\
\hline $21-30$ & $19(31)$ & $21(34)$ \\
\hline $31-40$ & $21(33)$ & $22(35)$ \\
\hline $41-50$ & $11(18)$ & $9(15)$ \\
\hline \multicolumn{3}{|c|}{ Site of parasymphysis fracture } \\
\hline Right & $34(55)$ & $32(52)$ \\
\hline Left & $28(45)$ & $30(48)$ \\
\hline
\end{tabular}

Frequency of post-operative infection and malocclusion at 6 weeks of surgery was slightly more but statistically non-significant in patients of group A as compared to group B patients (Table II).

Age and gender wise stratification also revealed non-significant difference in frequency of infection and malocclusion between group A and group B (Table III). 
Table II: Comparison of outcome variables at six weeks of treatment $(n=124)$

\begin{tabular}{|l|c|c|c|c|}
\hline \multicolumn{2}{|c|}{ Group } & $\begin{array}{c}\text { Group A (n=62) } \\
\mathbf{n}(\%)\end{array}$ & $\begin{array}{c}\text { Group B (n=62) } \\
\text { n (\%) }\end{array}$ & P-value* \\
\hline \multirow{2}{*}{ Infection } & Yes & $2(3)$ & $61(99)$ & 0.56 \\
\cline { 2 - 5 } & No & $60(97)$ & $0(0)$ & 0.15 \\
\cline { 2 - 5 } Malocclusion & Yes & $2(3)$ & $62(100)$ & \\
\hline
\end{tabular}

*P-value $\leq 0.05$ was considered statistically significant

Table III: Comparison of outcome variables after age and gender stratification at six weeks of treatment ( $n=124)$

\begin{tabular}{|c|c|c|c|c|c|c|c|}
\hline \multirow{2}{*}{\multicolumn{2}{|c|}{$\begin{array}{l}\text { Variables } \\
\text { Age (years) }\end{array}$}} & \multicolumn{3}{|c|}{ Infection } & \multicolumn{3}{|c|}{ Mal-occlusion } \\
\hline & & \multirow{2}{*}{$\begin{array}{c}\begin{array}{c}\text { Group A } \\
\text { (n=62) }\end{array} \\
0\end{array}$} & \multirow{2}{*}{$\begin{array}{c}\begin{array}{c}\text { Group B } \\
(n=62)\end{array} \\
0\end{array}$} & $P$-value* & $\begin{array}{c}\text { Group A } \\
(n=62)\end{array}$ & $\begin{array}{c}\text { Group B } \\
(n=62)\end{array}$ & $P$-value* \\
\hline \multirow{2}{*}{$\leq 20$} & Yes & & & \multirow{2}{*}{1.00} & 0 & 0 & \multirow{2}{*}{1.00} \\
\hline & No & 11 & 10 & & 11 & 10 & \\
\hline \multirow{2}{*}{$21-30$} & Yes & 0 & 0 & \multirow{2}{*}{1.00} & 0 & 0 & \multirow{2}{*}{1.00} \\
\hline & No & 19 & 21 & & 19 & 21 & \\
\hline \multirow{2}{*}{$31-40$} & Yes & 1 & 1 & \multirow{2}{*}{1.00} & 1 & 0 & \multirow{2}{*}{1.00} \\
\hline & No & 20 & 21 & & 20 & 22 & \\
\hline \multirow{2}{*}{$41-50$} & Yes & 1 & 0 & \multirow{2}{*}{1.00} & 1 & 0 & \multirow{2}{*}{1.00} \\
\hline & No & 10 & 9 & & 10 & 9 & \\
\hline \multicolumn{8}{|l|}{ Gender } \\
\hline \multirow{2}{*}{ Male } & Present & 1 & 0 & \multirow{2}{*}{1.00} & 1 & 0 & \multirow{2}{*}{1.00} \\
\hline & Not present & 37 & 37 & & 37 & 37 & \\
\hline \multirow[t]{2}{*}{ Female } & Present & 1 & 1 & \multirow{2}{*}{1.00} & 1 & 0 & \multirow{2}{*}{1.00} \\
\hline & Not present & 23 & 24 & & 23 & 25 & \\
\hline
\end{tabular}

$* P$-value $\leq 0.05$ was considered statistically significant

\section{Discussion}

The present study shows that most of the enrolled patients with parasymphysis fractures in both groups were of younger age group and predominantly of male gender. The predominant male numbers could be explained by the simple fact that men mostly work outside, hence their chances of involvement in assault, road traffic accidents, activities leading to falls, sport injuries etc. is relatively higher resulting in fractures. Due to the socio-religious nature of this region, females are less active in outdoor activities and therefore, significantly lower ratio of fractures is seen.
Both infection and malocclusion as post-operative complications were comparatively more frequent in patients undergoing transosseous wiring as compared to Miniplates technique. Similar results were observed in other studies. Post-operative infection and malocclusion after transosseous wiring was $15 \%$ and $10 \%$ respectively in a study carried at Armed Forces Institute of Dentistry, Rawalpindi, Pakistan ${ }^{12}$ and $1.5 \%$ and $0.2 \%$, respectively after miniplate osteosynthesis in Centre Hospitalier Universitaire Vaudois, Switzerland. ${ }^{15}$ This can be because of non-rigid fixation of transosseous wiring which does not provide sufficient inter-fragmentary stability during healing. It only serves the purpose of realignment of parts of the fractured bone segments and prevents their displacement by the muscles of mastication. 
Different studies have been carried out comparing the traditional methods of treatment with newer techniques. Theriot et al. compared compression plates, Miniplates and Transosseous wiring osteosynthesis. ${ }^{17}$ Similarly, Renton and Wiesenfeld compared miniplates with transosseous wiring osteosynthesis. ${ }^{18}$ All of these researchers have supported the rigid internal fixation as the treatment of choice. On the other hand, Moulton et al. found the traditional techniques superior to the newer techniques with regards to occurrence of postoperative complications. ${ }^{19}$ In the current study, the results show differences between frequency of complications in both the procedures. Although the comparison is clinically significant but statistically insignificant due to a small number of patients for comparison in each group as well as lesser number of patients with complications.

Our results regarding postoperative infection are comparable with that of international data. As according to Moreno et al., infection rates for MMF and plating were $4.4 \%$ and $12.5 \%$ respectively. ${ }^{20}$ Similarly Renton and Wiesenfeld have also provided nearly the same data for TOW (10\%) and plating $(15 \%) .{ }^{18}$ Higher infection rates for both groups were most probably due to the direct intraoral contamination of the fracture site from the intraoral incision. Other factors like type of fracture, kind of treatment used, timing of treatment, oral hygiene, presence of tooth in the line of fracture, osteosynthesis material as a foreign body, mobility of the fracture site, etc., may also be involved. Infected patients were treated with broad-spectrum antibiotics.

The second most common complication in our study was post-surgical malocclusion. Our results are more or less similar to those reported by Renton and Wiesenfeld ${ }^{18}$ and Moreno et al. ${ }^{20}$ (MMF=2.9\% and $8.3 \%$ for other groups). The presence of post-surgical malocclusion depends on the patient's dental condition, the number of fractures and their displacement, the reduction that can be achieved, the kind and time of immobilization. No doubt rigidity of the osteosynthesis material is an advantage because it allows for immediate jaw mobility, but it can also be a drawback, if it prevents correction of a postoperative malocclusion with MMF. ${ }^{20}$

Renton and Wiesenfeld reported MMF in all the three groups but in the plating group MMF was done on a temporary basis for a shorter duration. The malocclusion noted was minimal and was treated easily by corrective occlusal adjustment. Delayed union was defined as excessive mobility of the fracture site three to four weeks posttreatment. This occurred in $5 \%$ of the total patients. In MMF group, delayed union occurred in two patients (10\%), in TOW group one patient (5\%) while none of the plating group faced this complication. Our findings regarding delayed union are similar to those reported by Renton and Wiesenfeld. ${ }^{18}$

None of the patients included in this study required further surgical intervention and progressed to normal union by only prolonging the period of MMF. Non-Union means that the fracture is nonhealing and will not unite on its own. Radiographs show rounding off and sclerosis of the bone ends called eburnation. Fortunately, none of our patients faced this complication.

\section{Conclusion}

Post-operative complications like infection and malocclusion are slightly less in miniplate group as compared to transosseous wiring in the management of mandibular parasymphyseal fractures. Although there were relatively more complications in the transosseous wiring group, the use of trans-osseous wire osteosynthesis still gave considerably good results. This method can still be 
useful in centers that are less well equipped, and where access to rigid internal fixation is limited.

\section{References}

1. Naeem A, Gemal H, Reed D. Imaging in traumatic mandibular fractures. Quant Imaging Med Surg. 2017; 7(4): 469-79. Doi: 10.21037/qims.2017.08.06

2. Ghanem AW, Elhayes AK, Saad K. The management of unstable oblique infected mandibular fractures with a $2.3 \mathrm{~mm}$ mandibular osteosynthesis reconstruction bone plate. J Craniomaxillofac Surg. 2011: 39(8): 600-5. Doi: 10.1016/j.jcms.2010.12.002.

3. Cosimo N, Chiara V, Michele P, Paolina T, Calistri L, Franchi L, et al. Imaging of mandibular fractures: a pictorial review. Insights Imaging. 2020; 11: 2-15. Doi:10.1186/s13244-020-0837-0

4. Farwell GD. Management of symphyseal and parasymphyseal mandibular fractures. Oper Tech Otolaryngol. 2008; 19(2): 108-12

5. Saad KA, Nowair IM, Esa EF. Three dimensional miniplate fixation in the management of mandibular fractures. Eygpt Dent J. 2017; 66: 241-48. Doi: 10.1016/j.otot.2008.06.001

6. Rahman $P$, Aslam A, Yunus $M$, Luqman U, Saleem MM, Mughal J, et al. Optimal and efficient management of mandibular fractures. Pak Oral Dent J. 2015; 35(2): 198-203.

7. Shetty V, Atchison K, Leathers R, Black E, Zigler C, Belin TR. Do the benefits of rigid internal fixation of mandibular fractures justify the added costs? Results from a randomized controlled trial. J oral maxillofac Surg. 2008; 66(11): 2203-12. Doi:10.1016/j.joms.2008.06.058

8. Qureshi AA, Reddy UK, Warad NM, Badal S, Jamadar AA, Qurishi N. Intermaxillary fixation screws versus Erich arch bars in mandibular fractures: $A$ comparative study and review of literature. Ann Maxillofac Surg. 2016; 6(1): 25-30. Doi: 10.4103/2231-0746.186129

9. Ingole PD, Garg A, Shenoi SR, Badjate SJ, Budhraja N. Comparison of intermaxillary fixation screw versus eyelet interdental wiring for intermaxillary fixation in minimally displaced mandibular fracture: a randomized clinical study. J Oral Maxillofac Surg. 2014; 72: 958e1-e7. Doi: 10.1016/j.joms.2014.01.005

10. Anyanechi CE, Osunde OD, Saheeb BD. Complications of the use of trans-osseous wire osteosynthesis in the management of compound, unfavorable and non-comminuted mandibular angle fractures. Ghana Med J. 2016; 50(3): 172-9. PMID: 27752192

11. Khitab U, Tariq M. Outcome of rigid internal fixation of mandibular fractures: A prospective study. Pak Oral Dent J. 2009; 29: 207-11.

12. Amin $M$, Babar A, Ibrahim MW, Awan MUA. Postoperative Complications in Mandibular Fracture Management Comparison of Three Different Treatment Modalities. Pak Armed Forces Med J. 2016; 66(5): 720-25.

13. Rahim A, Waraich A. Mandible fractures osteosynthesis: A comparison of three techniques. Pak Oral Dent J. 2009; 29(2): 207-11.

14. Kumar BP, Kumar KJ, Venkatesh V, Mohan AP, Ramesh K, Mallikarjun K. Study of efficacy and the comparison between $2.0 \mathrm{~mm}$ locking plating system and $2.0 \mathrm{~mm}$ standard plating system in mandibular fractures. J Maxillofac Oral Surg. 2015; 14: 799-807. Doi: 10.1007/s12663-014-0718-5

15. Jaques B, Richter $M$, Arza A. Treatment of mandibular fractures with rigid osteosynthesis: using the AO system. J Oral Maxillofac Surg. 1997; 55(12): 1402-6. Doi: 10.1016/s0278-2391(97)906376

16. Seemann R, Lauer G, Poeschl PW, Schicho K, Pirklbauer $M, r$ Russmüller $G$, et al. CROOMA, complication rates of operatively treated mandibular factures, paramedian and body. Oral Surg Oral Med Oral Pathol Oral Radiol Endod. 2011; 111: 449-54. Doi:10.1016/j.tripleo.2010.06.008

17. Theriot BA, Van Sickels JE, Triplett RG, Nishioka GJ. Intraosseous wire fixation versus rigid osseous fixation of mandibular fractures: a preliminary report. J Oral Maxillofac Surg. 1987; 45(7): 577-82. Doi: 10.1016/0278-2391(87)90267-9

18. Renton TF, Wiesenfeld D. Mandibular fractures osteosynthesis: a comparison of three techniques. Br J Oral Maxillofac Surg. 1996; 34(2): 166-73. Doi: 10.1016/s0266-4356(96)90372-1

19. Moulton BR, Rubinstein AJ, Salzhauer MA, Brown M, Angulo J, Alster $C$, et al. Complications of mandibular fractures. Ann Plast Surg. 1998; 41(3): 258-63. Doi: 10.1097/00000637-199809000-00006

20. Moreno JC, Fernandez A, Ortiz JA, Montalvo JJ. Complication rates associated with different treatments for mandibular fractures. J Oral Maxillofac Surg. 2000; 58(3): 273-81. Doi: 10.1016/s0278-2391(00)90051-x 